Farm animal welfare - who writes the rules?

Occasional Publication No. 23 - British Society of Animal Science 1999

edited by A. J. F. Russel, C. A. Morgan, C. J. Savory, M. C. Appleby and T. L. J. Lawrence

\title{
Initiation of suckling in suckler cows with natural and adopted calves
}

\author{
H. D. Randle
}

Department of Agriculture and Food Studies, Seale-Hayne Faculty, University of Plymouth, Newton Abbot TQ12 6NQ

\section{Introduction}

Wild bovines such as water buffalo have been observed to adopt orphans (Murphey et al., 1991). Spontaneous adoption has also been reported in domestic bovines and occurs either as a result of the dams mismothering by poaching young or permitting young other than their own to suck, or due to the opportunistic tendencies of young calves. The bond between a beef cow and her calf is considered to be less flexible than that between a dairy cow and her calf (Le Neindre, 1989). This difference is attributed to beef cows having been selected for early calf recognition and strong bonding (Kiley-Worthington and de la Plain, 1983) and dairy cows having been selected for amenability to the removal of the calf and milk let down in its absence (Edwards and Broom, 1982). Nevertheless, it is possible to manipulate the beef cow into accepting a second calf in addition to her own, although there can be problems with this since calves are typically only fostered (tolerated and not treated as her own). A system in which calves are only fostered can be time consuming as the sucking may require human supervision. However, Kiley-Worthington (1976) developed a double-suckling system involving adoption in which the additional calf (the 'adopter') is treated by the (beef) cow in a similar way to her own calf (the 'natural'). The sucking behaviour of calves raised in this system is studied further in this paper.

Suckling has been found to play an important rôle in the reinforcement of the mother-young bond (Le Neindre, 1982). There are conflicting results regarding who controls the occurrence and length of suckling bouts. Lent (1991) reported that dams initiated the majority of suckling bouts in the first few weeks post partum, whilst earlier, Vitale et al. (1986) reported that calves initiated $87 \%$ of suckling bouts in this period. Clearly calves play an important rolle in the initiation of suckling. The objective of the studies reported in this paper was to compare the number of suckling bouts initiated by natural and adopted calves sucking beef cows.

\section{Material and methods}

A total of 13 trios were observed, each consisting of a South Devon cow, her homebred natural calf and an adopted calf. Adoptions were carried out using the method developed by Kiley-Worthington (1976). The adoptee was usually at least 3 days old at the time of adoption. The potential adoptee was fed and covered with amniotic fluid, before being introduced to the dam alongside her natural calf immediately after the natural calf had sucked for the first time. It was important to ensure that the adoptee was not hungry at the point of first introduction to the dam. For the first 2 to 3 days post partum the calves were separated from the dam. They were put into an adjacent pen which allowed visual, vocal and tactile contact between the dam and calves. The calves were then reunited with the dam simultaneously for suckling. Suckling was closely supervised as it was important that the dam learned to tolerate the adoptee and that the adoptee was not put off. The dam was tied up and the adoptee only allowed to suck for a maximum of $5 \mathrm{~min}$ (to prevent scouring and consequent separation of the dam and adopted calf). By day 4 if possible the dam was untied and the adoptees sucking was unrestricted. Typically by day 5 the two calves remained with the cow between suckling sessions. By day 7 the trio was turned out to pasture and observed periodically to check that the adoptee was permitted to suck the adoptive dam.

In group 1, six trios were observed for the 1st week of the adoption and week 3 post adoption. In group 2 , seven trios were observed during the 1 st week of the adoption and the 1st week of month 5 post adoption. During these observation periods all suckling bouts which occurred between 06.00 and $21.00 \mathrm{~h}$ were observed. Observations included all of the behaviours exhibited by the darn and both the natural and adopted calves. The identity of the initiator of the suckling bout was recorded (dam, natural, adoptee, human). The frequencies of the following behaviours directed by the dam towards both the natural and adopted calf were recorded: contact making, head throwing, head butting, 
stamping, leg lifting, weight shifting, smelling, licking, calling, head shaking and chasing. The frequencies of the following behaviours directed by the natural and adopted calf towards the dam were recorded: approaching, contact making, touching body, teat searching, smelling the udder, sucking, bunting, tail wagging, contact breaking, head shaking, following and calling. The sucking positions assumed and durations achieved in each position were also recorded for both calves, as were any necessary incidences of intervention by the human supervisor. All of these behaviours were recorded instantaneously from the point of initiation to the end of the suckling session.

At the end of the four observation periods the success of the adoptions were rated using the fivepoint system developed by Kiley-Worthington and de la Plain (1983): R - rejected, the calf was persistently attacked by the dam and not allowed to suck; F1 - level one fostering, the calf was tolerated, it was allowed to suck adjacent to the natural calf or from between the hind legs; F2 - level two fostering, as F1 but the calf was also allowed to suck on the opposite side to the natural calf; $\mathrm{A} 1$ - level one adoption, as F2 but could also suck alone if the dam was distracted; A2 - level two adoption, calf permitted to suck alone without the dam being distracted and there was evidence of the dam actively seeking the calf out and protecting it.

In this study, the majority $(70 \%)$ of the suckling sessions in group 1, week 1 were initiated by the human supervisor. This was controlled to ensure acceptance of the adoptee calf as outlined above. In group 2, week $40 \%$ of the suckling sessions were initiated by the human supervisor.

\section{Results}

At the end of the 1st week of adoption 12 of the 13 adoptions carried out were considered to be successful, i.e. the cow had 'adopted' the second calf and no human intervention was necessary to ensure successful suckling (Table 1).

In total 409 suckling sessions were observed. In both groups the number of initiations performed by the humans decreased dramatically after the 1st week of the adoption (Figure 1). In all observation periods the natural calves initiated substantially more of the suckling sessions than the adopted calves. In both follow up observation periods (week 3 post adoption in group 1 and the 1st week of month 5 post adoption in group 2) dams initiated more suckling sessions than the adopted calves. In fact, adopted calves seldom initiated suckling sessions. It was found that adopted calves had developed an 'opportunistic' strategy which allowed them to suck.
Table 1 The success ratingt of the 13 adoptions studied at the end of week 1 of the adoption

\begin{tabular}{lccccccr}
\hline \hline Group 1 & dam & & & & & & \\
& 1 & 2 & 3 & 4 & 5 & 6 & \\
\hline & A1 & A1 & A1 & A2 & A1 & A1 & \\
\hline Group 2 & dam & & & & & & \\
& 1 & 2 & 3 & 4 & 5 & 6 & 7 \\
\hline & A1 & A1 & A1 & A2 & A2 & A2 & R
\end{tabular}

$+\mathrm{R}=$ rejection; $\mathrm{A}=$ adoption: 1 = calf sucks when dam is distracted; 2 = calf sucks without dam being distracted.

Adopted calves waited for their natural calf partner to commence sucking before they sucked the dam. This opportunistic strategy was still employed at 5 months post adoption. It can be seen in Figure 1 that in group 2 ( 5 months post adoption) there were some human interventions. However, these were all performed on the one trio in which adoption was not achieved and the calf was rejected.

\section{Discussion}

Double suckling with adoption

The double suckling with adoption method used was successful. One of the 13 adoptions failed, although the additional calf was allowed to suck if the dam was under close human supervision.

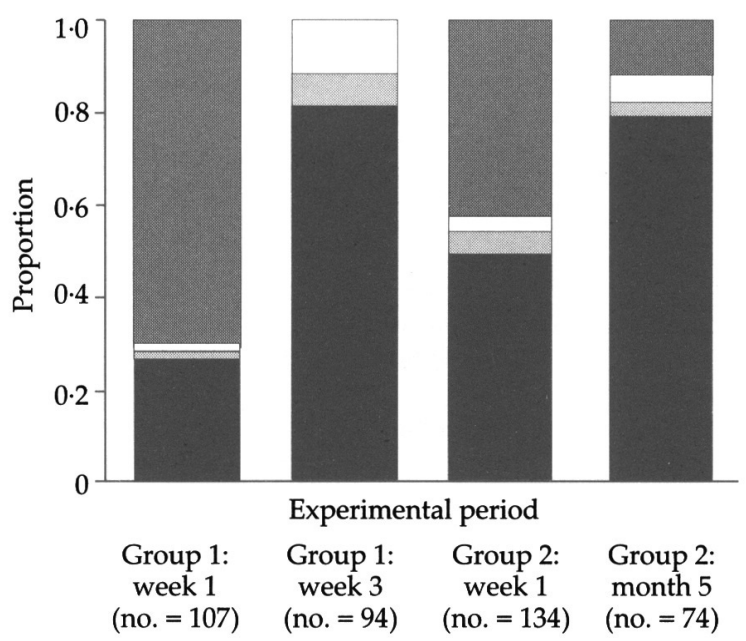

Figure 1 Proportion of suckling initiations by natural calves ( $\square$ ), adopted calves ( $\square)$, dams () and humans (ㅁ) intervention. 


\section{Initiation of suckling}

The sucking behaviour of all of the calves studied was typical of calves in a beef suckler system. The natural calves took responsibility for controlling suckling sessions (Vitale et al., 1986; Veissier et al., 1990) from week 1 post adoption and by the follow up observation periods (week 3 in group 1 and month 5 in group 2) the calves initiated most of the suckling sessions (Giovengo and Waring, 1990). Throughout the study the natural calves initiated substantially more suckling sessions than the adoptee calves. Adoption was achieved since adoptee calves were permitted to suck without human supervision, however they seldom initiated the suckling session and were rarely observed sucking without the natural calf. In order to suck and obtain milk, adoptee calves developed an opportunistic strategy, in which they waited for their natural counterpart to initiate suckling. The importance of the synchronization of suckling in ensuring that the two offspring will be able to suck successfully on one dam has been highlighted by Price et al. (1984) in beef cows rearing twins and Birgersson et al. (1991) in deer. This study demonstrated that the synchronization of suckling is equally important when the beef cow has adopted an additional calf to her own and that the adoptee develops an opportunistic strategy to ensure suckling success part of which involves waiting for the natural calf to initiate the suckling session.

\section{Acknowledgements}

This work was undertaken as part of a Ph.D. at the University of Exeter. The author is extremely grateful to Dr Marthe Kiley-Worthington and Mr Chris Rendle for the use of their cattle.

\section{References}

Birgersson, B., Ekvall, K. and Temrin, H. 1991. Allosuckling in Fallow deer, Dama dama. Animal Behaviour 42: 326-327.

Edwards, S. A. and Broom, D. M. 1982. Behavioural interactions of dairy cows with their newborn calves and the effects of parity. Animal Behaviour 30: 525-535.

Giovengo, S. L. and Waring, G. H. 1990. Social development of the American bison calf. Proceedings of the Society for Veterinary Ethology summer meeting, 15-17 May, Edinburgh.

Kiley-Worthington, M. 1976. Fostering and adoption of beef cattle. Digest - British Cattle Breeders Club 31: 42-55.

Kiley-Worthington, M. and de la Plain, S. 1983. The behaviour of beef suckler cattle (Bos taurus). Birkhauser Verlag, Basel.

Le Neindre, P. 1982. Cow-calf relationships: the effects of management type. In Welfare and husbandry of calves (ed. J. P. Signoret), pp. 5-15. Martinus Nijhoff, London.

Le Neindre, P. 1989. Influence of rearing conditions and breed on social relationships of mother and young. Applied Animal Behaviour Science 23: 117-127.

Lent, P. C. 1991. Maternal-infant behaviour in Muskoxen. Mammalia 55: 3-23.

Murphey, R. M., Paranhos da Costa, M. J. R, de Souza Lima, L. O. and de Moura-Duarte, F. A. 1991. Communal suckling in Water Buffalo (Bubalis bubalis). Applied Animal Behaviour Science. 28: 341-352.

Price, E. O., Martinez, C. L and Coe, B. L. 1984. The effects of twinning on mother-offspring behaviour in range beef cattle. Applied Animal Behaviour Science 13: 309-320.

Veissier, I., Le Neindre, P. and Garel, J. P. 1990. Decrease in cow-calf attachment after weaning. Behavioural Processes 21: 95-105.

Vitale, J. F., Tenucci, M., Papini, M. and Lovari, S. 1986. Social behaviour of the calves of semi-wild Maremma cattle, Bos primigenius taurus. Applied Animal Behaviour Science 16: 217-231. 